\title{
In vivo electroporation in DNA-VLP prime-boost preferentially enhances HIV-1 envelope-specific IgG2a, neutralizing antibody and CD8 T cell responses
}

Xun Huang, ${ }^{\mathrm{a}, *}$ Qianqian Zhu,,${ }^{\mathrm{a},}$ Xiaoxing Huang, ${ }^{\mathrm{b}}$ Lifei Yang, ${ }^{\mathrm{a}, \mathrm{S}}$ Yufeng Song, ${ }^{\mathrm{a}}$ Ping Zhu, ${ }^{\mathrm{b}}$ and Paul Zhou ${ }^{\mathrm{a}, \#}$ 


\section{Abbreviations}

18 EP: electroporation

19 DDVV: priming twice with DNA plasmids and boosting twice with HIV-1 VLP

20 VLP: virus-like particles

21 RB: recombinant baculovirus

22 c-di-GMP: cyclic diguanosine monophosphate

23 TCA: trichloroacetic acid

24 BSA: bovine serum albumin

25 SHIV: simian-human immunodeficiency virus

26 
Although in vivo electroporation (EP) has been utilized to improve immunogenicity in DNA vaccines alone or in prime-boost regimens with both proteins and viral-vectors, no studies on in vivo EP in DNA-VLP prime-boost regimens against HIV-1 have been reported. Previously we developed stably transfected Drosophila S2 clones to produce HIV-1 virus-like particles (VLP) and demonstrated that priming mice twice with DNA plasmids encoding HIV-1 gp120 and gag and boosting twice with HIV-1 VLP (i.e. DDVV immunization) elicited both envelope-specific antibody and envelope and gag-specific CD8 T cell responses. However, the potency and the breadth of immunogenicity still need to be improved. In this study we tested the effect of in vivo not IgG1, antibody responses were significantly higher in DDVV + EP than in DDVV. Moreover, antibody responses, but also cross-neutralizes four of five other HIV-1 strains tested, including two tier 2 strains. Finally, although CD4 and CD8 T cells from both DDVV and DDVV + EP immunizations secreted IFN- $\gamma$, IL-2, TNF- $\alpha$ upon HIV-1 envelope peptide stimulation, average HIV-1 envelope-specific CD8 T cells that secreted IFN- $\gamma$, IL-2 and/or TNF- $\alpha$ were significantly higher in DDVV + EP than in DDVV. Thus we conclude that DDVV + EP immunization

47 preferentially increases HIV-1 envelope-specific $\mathrm{T}_{\mathrm{H}} 1$ cytokine-mediated IgG2a responses and significantly enhances the potency and the breadth of neutralizing antibody responses including tier 2 viruses. Further study on this heterologous regimen in large animals is warranted. 
50 Keywords. Heterologous prime-boost vaccination, in vivo electroporation, HIV-1, IgG

51 subclasses, neutralizing antibody and $\mathrm{T}$ cell responses

52

$53 \quad$ Highlights.

54 1. DDVV + EP immunization preferentially increases HIV-1 envelope-specific IgG2a responses.

55 2. DDVV + EP immunization significantly enhances $n A b$ responses including tier 2 viruses.

56 3. DDVV + EP immunization significantly enhances HIV-1 envelope-specific CD8 T cell

57 responses.

58 
An effective vaccine against HIV-1 requires both humoral and cellular immune responses

61 [1]. The RV144 trial that combined a pox virus-vectored gp120 prime with a gp120 protein boost

62 demonstrated a $31.2 \%$ reduction in HIV-1 acquisition at 42 months following initial vaccination

63 [2]. Subsequent immune correlation studies indicate that broadly neutralizing antibody responses

64 were not found to be a correlate of efficacy; whereas IgG antibody responses to V1/V2 or V3

65 loop of HIV-1 gp120 correlates with decreased HIV-1 transmission risk in RV144 [3, 4].

66 Immunization of rhesus macaques with live rhesus cytomegalovirus (CMV) vector encoding SIV

67 gag, pol, rev, nef, tat and envelope provides a powerful stimulation of SIV-specific CD8 T cells

68 that control and eliminate virus in 50\% of animals, although it does not prevent initial infection

$69[5,6]$. Subsequent study found that SIV protein-expressing rhesus CMV vectors elicited SIV-

70 specific CD8 T cells that recognize unusual, diverse and highly promiscuous epitopes, including

71 epitopes restricted by MHC class II molecules [7]. Therefore, a vaccine regimen that could elicit

72 both broad HIV-1-specific antibody and CD8 T cell responses are highly desirable [8-10].

In vivo electroporation (EP) has been utilized to improve immune responses to DNA

74 vaccines as candidate HIV-1 vaccines in standalone [11-24] or in prime-boost regimens with

75 both proteins [25-30] and viral-vectored [31-35] vaccines in several animal models and, more

76 recently, in human clinical trials $[36,37]$. The results clearly show that co-administration of

77 localized electrical fields by in vivo EP significantly increases the immunogenicity of DNA

78 vaccines [38, 39]. For example, in standalone DNA vaccines Liu et al. tested a HIV-1 envelope

79 DNA vaccine with or without in vivo EP in mice and demonstrated that in vivo EP augmented

80 cellular and humoral immune responses and allowed a 10-fold reduction in vaccine dose.

81 Furthermore, they showed that in vivo EP also recruited large number of macrophages, DCs, T 
82 and B cells to the site of inoculation [12]. Luckay et al. demonstrated that in a non-human

83 primate model a 10 to 40 -fold increase in HIV-1-specific cellular immune responses and over

84 100-fold increase in ELISA-binding antibody responses [15]. Vasan et al. tested ADVAX, a

85 multigenic HIV-1 DNA vaccine candidate, with or without in vivo EP in healthy human

86 volunteers and demonstrated that in vivo EP is safe, tolerable and effective in improving the

87 breadth, potency and durability of cellular immune responses to a DNA vaccine [36]. In

88 heterologous DNA-protein prime-boost regimens both Muthumani et al. [25] and Zhang et al.

89 [26] demonstrated that in small animal models in vivo EP induced significantly higher antibody

90 binding titers that neutralized several tier 1 viruses [25] or $\mathrm{BC}$ recombinant envelope-

91 pseudotyped viruses [26]. In heterologous DNA-viral vector prime-boost regimens Winstone et

92 al. showed that in vivo EP of a mixture of DNA vaccines encoding multiple SIV antigens in

93 conjunction with IL-12, followed by boosting with a recombinant Ad5-based vaccine expressing

94 SIV antigens led to partial protection from a repeat low dose mucosal SIVmac239 challenge with

95 strong virus set point control in the majority of animals [31]. Thus, collectively these studies

96 demonstrated that in vivo EP induces a transient state of membrane permeability to facilitate

97 uptake of DNA plasmid in the surrounding interstitial spaces and recruits large number of 98 immune cells to the site of immunization $[38,39]$. Surprisingly, although in vivo EP has been 99 utilized to DNA vaccines alone or in prime-boost regimens with both proteins and viral-vectored 100 vaccines [25-29, 31-37], to our knowledge no studies on the effect of in vivo EP on 101 immunogenicity against HIV-1 elicited by DNA-virus-like particles (VLP) prime-boost regimens 102 have been reported.

103 Previously we developed a novel system to produce HIV-1 VLP using stably transfected 104 Drosophila S2 cell clones [40]. We demonstrated that the amount of HIV-1 VLP produced by S2 
105 cell clones is comparable to that produced by insect cells infected with recombinant 106 baculoviruses (RB) [41] and much higher than those produced by mammalian cells [42-47]. 107 Unlike HIV-1 VLP produced by insect cells infected with RB, culture supernatants produced by 108 stably transfected S2 cell clones are not contaminated with recombinant viruses, which makes 109 downstream purification process simpler. We also demonstrated that priming mice twice with 110 DNA plasmids encoding HIV-1 gp120 and gag and boosting them twice with stable Drosophila 111 S2 transfectant-produced VLP elicited both envelope-specific antibody responses and envelope 112 and gag-specific CD8 T cell responses [40]. However, the potency and the breadth of immune 113 responses still need to be improved.

114 Therefore, in this study we tested the effect of in vivo EP during DNA priming on 115 immunogenicity in this heterologous DNA-VLP prime-boost regimen. Post-immune sera and 116 splenocytes were collected after the second boost. HIV-1 envelope-specific ELISA-binding and 117 neutralizing antibody responses as well as envelope-specific CD4 and CD8 T cell responses were 118 carefully evaluated. 
Cell lines. Stably transfected Drosophila S2 cell clone B2 was previously generated in our 122 laboratory and cultured as described before [40]. The 293 FT cell line was bought from 123 Invitrogen Life Technologies and cultured as described previously [48]. TZM.bl cells were 124 obtained from the NIH AIDS Research and Reference Reagent Program (ARRRP; Germantown, 125 MD) $[49,50]$ and mouse fibroblast cell line L929 (Cat\# CCL-1) were purchased from American 126 Tissue Culture Company (ATCC, Manassas, VA) [51]. Both cell lines were cultured in complete 127 DMEM media supplemented with $10 \%$ FBS, $1 \mathrm{mM}$ sodium pyruvate, $2 \mathrm{mM}$ L-glutamine and 128 penicillin/streptomycin $[100 \mathrm{U} / \mathrm{ml}$ each $]$ with $\mathrm{CO}_{2}$ at $37^{\circ} \mathrm{C}$.

129 Antibodies. Human anti-gp120 antibody 2G12 and mouse anti-HIV-1 Gag p24 antibody 183130 H12-5C were obtained from the ARRRP. Human anti-gp120 antibodies VRC01, PGT128 and 131 10-1074 and control antibody 100F4 (a human anti-H5 hemagglutinin antibody) were produced 132 and purified in our laboratory by using stably transfected S2 clones as described before [52]. 133 llama antibody JM4 [53] was produced and purified in our laboratory by using prokaryotic 134 expression and Ni-NTA affinity chromatography. PreCP-conjugated anti-CD4, allophycocyanin 135 (APC)-conjugated anti-CD8, fluorescein isothiocyanate (FITC)-conjugated anti-IFN- $\gamma$, 136 phycoerythrin (PE)-conjugated anti-IL-2, phycoerythrin (PE)-Cy7-conjugated anti-TNF- $\alpha$, 137 purified anti-CD28 and anti-CD49d antibodies were all bought from BD Bioscience (Mountain 138 View, CA).

139 Gene constructs. Plasmids CMV/R-gp120 (consensus B) were generated for mammalian 140 expression in our laboratory previously [40]. 
141 Production of HIV-1 VLP by a stable S2 clone. HIV-1 VLP production and quantification 142 were as described before $[40,52]$.

143 Transfection and western blot analysis. To test the mammalian expression of gp120, L929

144 cells $\left(10^{5}\right)$ were transiently transfected with $1.6 \mu \mathrm{g}$ of plasmid CMV/R-gp120 (consensus B) 145 using Lipofectamine ${ }^{\circledR}$ LTX \& PLUS ${ }^{\text {TM }}$ Reagent (Invitrogen). Culture supernatants were 146 harvested 2 days post transfection, precipitated with trichloroacetic acid (TCA), and resuspended 147 in PBS. Samples were loaded and separated through 10\% SDS-PAGE and then transferred onto 148 PVDF membranes (Millipore). The membranes were blocked in TBST containing nonfat dry 149 milk (5\%) and sequentially probed with the antibodies specific for HIV-1 gp120 as well as for $\beta$ 150 actin control. Antigens were visualized with HRP-conjugated anti-human IgG antibody (Abcam) 151 or HRP-conjugated anti-mouse IgG antibody (ICL), respectively, and follow by EZ-ECL 152 substrate staining (Thermo).

153 FACS analysis. To test the antigenicity of consensus B HIV-1 envelope proteins on the surface 154 of a stably transfected S2 clone B2, stably transfected cells were incubated with a panel of 155 human monoclonal antibodies VRC01, 2G12, PGT128 and 10-1074, a llama antibody JM4 or 156 control antibody 100F4 for 1 hour on ice. Then cells were subsequently washed twice with 157 FACS buffer (PBS containing $1 \%$ FBS and $0.02 \% \mathrm{NaN}_{3}$ ) and stained with FITC-conjugated anti158 human IgG antibody (Sigma) or mouse anti-his tag antibody followed by PE-conjugated goat 159 anti-mouse IgG antibody (Sigma) for another 30 minutes on ice. Cells were then washed and 160 fixed with 2\% formaldehyde in FACS buffer. FACS analysis was performed with a LSRII flow 161 cytometer (BD Biosciences). 
163 Immunization and sampling. Animal protocols were all approved by the Institutional Animal 164 Care and Use Committee of the Institut Pasteur of Shanghai (Approval No. A2011014 \& 165 A2014011). Six to eight weeks old female BALB/c mice were purchased and housed as 166 described previously [40]. Mice were divided into three groups randomly (6 or 9 mice per group) 167 for the immunization. DNA immunizations were performed after anesthetization with $65 \mathrm{mg} / \mathrm{kg}$ 168 pentobarbital sodium. Mice in group 1 were injected intramuscularly (i.m.) in both hind legs or 169 subcutaneously (s.c.) with $100 \mu$ of PBS. Mice in group 2 were i.m. primed twice with $50 \mu$ g of 170 plasmid CMV/R-gp120 (consensus B) and boosted twice subcutaneously (s.c.) with HIV-1 VLP 171 (consensus B) equivalent to $5 \mu \mathrm{g}$ of HIV-1 gp120 plus $5 \mu \mathrm{g}$ of c-di-GMP adjuvant [54]. Mice in 172 group 3 were primed and boosted in the same way as in group 2 except that during the priming 173 DNA were delivered by in vivo EP using the EPT-I delivery device (TERESA, Shanghai, China). 174 A central injection needle along with a needle electrode pair with $5 \mathrm{~mm}$ spacing in between was 175 inserted into both hind legs shaved. And the DNA vaccination process consisted of 6 pulses at $17660 \mathrm{~V}$ constant voltage, each with $50 \mathrm{~ms}$ duration and $1 \mathrm{~s}$ interval $[55,56]$. DNA prime were given 177 on day 0 and 21 followed by HIV-1 VLP/c-di-GMP boost on day 49 and 77. Seven days before 178 the first prime and ten days after the second boost, serum samples were collected by retro-orbital 179 plexus puncture, heat inactivated and stored in aliquots at $-80^{\circ} \mathrm{C}$. Spleens were harvested 10 days 180 after the boost and splenocytes were isolated for intracellular cytokine staining (see below).

181 ELISA. Total IgG, IgG1, and IgG2a antibody responses against consensus B gp120 were 182 measured as described before with HRP-conjugated anti-mouse IgG (1:5,000) (ICL), anti-mouse 183 IgG1 (1:500) or anti-mouse IgG2a (1:500) antibodies (SBA), respectively [40]. $\mathrm{EC}_{50}$ value to a 184 given serum was determined as a serum dilution that results in $50 \%$ of the maximum anti-HIV-1 185 gp120 binding. 
186 HIV-1 pseudotypes and a single-cycle infectivity assay. HIV-1 pseudotypes were generated

187 and single-cycle infectivity assay was accomplished as described previously [40, 48].

188 Intracellular cytokine staining (ICS). ICS was performed as described before [40], except that 189 splenocytes were stimulated with a mixture of ten 15 -mer peptides $(2.5 \mu \mathrm{g}$ of each peptide/ml $)$ 190 derived from consensus B HIV-1 envelope protein (Table 1) [44], along with anti-mouse CD28 191 and anti-mouse CD49d antibodies. A total of $10^{6}$ cells were acquired per sample on a LSRII flow 192 cytometer (BD Biosciences) and analyzed using FlowJo software.

193 Statistics. Data analyses were performed with GraphPad Prism v5.0. An unpaired Student $t$ test 194 was utilized to compare two sets of data. Exact Spearman rank correlation method was used to 195 assess the correlations between the ELISA-binding antibody responses and between neutralizing 196 antibody responses. All $P$ values are two-trailed. 


\section{Results}

\section{Immunogen characterization}

To characterize DNA plasmid expressing consensus B gp120, we transfected mouse cell line

201 L929 with or without DNA plasmids encoding consensus B gp120 and/or HIV-1 rev. Fig. 1A shows that HIV-1 gp120 were produced in the mouse cell line and secreted into the culture supernatants with or without co-transfection of gene encoding HIV-1 rev.

204

Previously, we stained stably transfected Drosophila S2 clones using human anti-HIV-1 envelope antibodies 2G12, VRC01, b12 PG16 and 4E10 along with control antibody 100F4 to determined the antigenicity of HIV-1 VLP. We found that except for PG16 epitope, epitopes 2G12, b12, VRC01 and 4E10 tested are present on spikes of HIV-1 VLP produced by S2 clones [40]. Since then, many new broadly neutralizing monoclonal antibodies that recognize different epitopes on HIV-1 envelope have been discovered [57]. So to further characterize the antigenicity of HIV-1 VLP, in this study, we stained stably transfected Drosophila S2 cell clone with three new antibodies JM4, 10-1074 and PGT128 along with 100F4 control, VRC01 and 2G12. JM4 is an Llama single domain antibody that recognizes an epitope comprising both CD4 and coreceptor binding sites [53]. 10-1074 and PG128 are two human antibodies that recognize

214 high mannose patch epitope centered on N137, N301, N332 and N397 glycans [58, 59]. Fig. 1B 215 shows that stably transfected S2 cell clone can be well stained by all five anti-envelope 216 antibodies, but not control antibody 100F4. Thus we concluded that the broad neutralization 217 epitopes 2G12, VRC01, JM4, 10-1074 and PG128 are preserved on spikes of HIV-1 VLP 218 produced by S2 cell clones. 
Fig. 2 summarizes the immunization and sampling schedule as well as assays to measure

222 HIV-1 specific antibody and T cell responses. Fig. 3A shows that although both DDVV and

223 DDVV + EP immunizations elicited consensus B gp120-specific ELISA-binding total IgG

224 antibody responses as compared to PBS control group $(P<0.001$ for both groups), average EC50

225 was significantly higher in DDVV + EP group $(4,829 \pm 527)$ than in DDVV group $(2,575 \pm 268)$

$226(P=0.006)$. Thus, we concluded that in vivo EP during DNA priming significantly enhances

227 HIV-1 gp120-specific total IgG responses elicited by DDVV immunization.

Fig. 3B shows that both DDVV and DDVV + EP sera exhibited consensus B gp120-specific

ELISA-binding IgG1 antibody responses as compared to control group $(P=0.002$ for both groups) and no significant difference in $\mathrm{EC}_{50}$ values $(6,336 \pm 1,101$ in DDVV vs. 7,630 $\pm 1,216$ in

$\mathrm{DDVV}+\mathrm{EP})$ between the two groups $(P=0.4721)$. In contrast, average $\mathrm{EC}_{50}$ value in consensus $5,945)$ in DDVV + EP group than $(1,654 \pm 634)$ in DDVV group $(P=0.032)$ (Fig. 3C). Interestingly, there was a positive correlation between $\mathrm{EC}_{50}$ values of anti-HIV-1 gp120 total IgG and IgG2a responses in DDVV + EP group (Fig. 4A), but not in DDVV group (Fig. 4B). Thus taken together these results indicate that in vivo EP during DNA priming in DDVV

237 immunization preferentially enhances $\operatorname{IgG} 2$ a responses.

In vivo EP in DNA priming in the DDVV immunization significantly enhances neutralizing antibody responses against diverse $H I V-1$ strains

To test the effect of in vivo EP in DNA priming on neutralizing antibody responses elicited by DDVV immunization, an HIV-1 pseudotype-based neutralization assay was performed against a panel of HIV-1 pseudotypes along with VSV-G pseudotype control. The panel consists of HIV-1 envelopes derived from clade A (Q168), clade B (consensus B, HxBc2 and Yu2), clade 
$244 \mathrm{C}$ (consensus C) and CRF01_AE recombinant (CNE3). Among them Q168 and Yu2 belong to 245 tier 2 strains. Fig 5 shows that although DDVV immunization elicited anti-autologous consensus 246 B specific neutralizing antibody responses with average 42.5\% neutralization activity at 1:50 247 serum dilution as compared to PBS control $(P=0.0002)$, it failed to cross-neutralize all other 248 five HIV-1 strains. In contrast, DDVV + EP immunization not only elicited enhanced anti249 autologous consensus B specific neutralizing antibody responses with average 59.3\% 250 neutralization activity at 1:50 serum dilution as compared to DDVV immunization $(P=0.0347)$, 251 but also cross-neutralizes four other HIV-1 strains $\mathrm{HxBc} 2, \mathrm{Yu} 2$, Q168 and CNE3 with average $25242.93,32.5,47.98$, and 39.31\% neutralization activity at 1:50 serum dilution, respectively.

253 Statistically, all are significantly different from DDVV immunization with $P$ values of 0.0186 , $254<0.0001,<0.0001$ and 0.0057, respectively. Both DDVV and DDVV + EP immunizations did 255 not elicit cross-neutralization activity against consensus C pseudotypes and VSV-G pseudotype 256 control. Interestingly, in DDVV + EP group there are positive correlations between 257 neutralization activities against autologous consensus $\mathrm{B}$ and $\mathrm{Yu} 2$ strains $(\mathrm{R} 2=0.7119)($ Fig. 6A) 258 and against autologous consensus $\mathrm{B}$ and Q168 strains $(\mathrm{R} 2=0.4447)$ (Fig. 6B). Thus we 259 conclude that the in vivo EP in DNA priming in the DDVV immunization significantly enhances 260 neutralizing antibody responses against a number of autologous and heterologous envelope 261 proteins including tier 2 strains.

262 In vivo EP in DNA priming in DDVV immunization significantly enhances HIV-1 envelope263 specific CD8, but not CD4, $T$ cell responses

264 To test the effect of in vivo EP in DNA priming on $\mathrm{T}$ cell responses elicited by DDVV 265 immunization, splenocytes from DDVV or DDVV + EP immunized and PBS control mice were 266 assayed against a mixture of 10 15-mer peptides derived from consensus B envelope protein 
267 (Table 1) using intracellular cytokine staining for IFN- $\gamma$, IL-2 and TNF- $\alpha$ in CD4 or in CD8 (Fig.

268 7) T cells. Compared to CD4 T cells from PBS control mice, CD4 T cells from DDVV or DDVV

$269+$ EP immunized mice exhibited higher, but statistically insignificant, HIV-1 envelope peptide-

270 specific responses; and between DDVV and DDVV + EP mice there are also no significant

271 differences (data not shown). Fig. 7A shows the gating strategy of single or double cytokine-

272 secreted CD8 T cells upon peptide stimulation. CD8 T cells from DDVV or DDVV + EP

273 immunized mice exhibited significantly higher HIV-1 envelope peptide-specific responses than

274 PBS control mice. Except for CD8 T cells that secreted IL-2, on average 0.314 and $1.151 \%$ of 275 CD8 T cells secreted IFN- $\gamma, 0.113$ and $0.211 \%$ secreted IL-2, 0.392 and $1.29 \%$ secreted TNF- $\alpha$, $276 \quad 0.035$ and $0.177 \%$ secreted both IFN- $\gamma$ and IL-2, 0.231 and $1.00 \%$ secreted both IFN- $\gamma$ and TNF$277 \alpha$, and 0.024 and $0.170 \%$ secreted both TNF- $\alpha$ and IL-2 in DDVV or DDVV + EP immunized 278 mice, respectively (Fig. 7B and G). Importantly, except for CD8 T cells that secreted IL-2, 279 between DDVV and DDVV + EP groups there were statistically significant differences $(P=$ 2800.0032 for IFN- $\gamma ; P=0.0027$ for TNF- $\alpha ; P=0.0127$ for both IFN- $\gamma$ and IL- $2 ; P=0.0024$ for 281 both IFN- $\gamma$ and TNF- $\alpha$; and $P=0.0091$ for both TNF- $\alpha$ and IL-2) (Fig. 7B and G). 
291

\section{Discussion}

Although in vivo EP has been utilized to improve immune responses to DNA vaccines alone or in prime-boost regimens with both proteins and viral-vectored vaccines against HIV-1 [11-29, 31-37], to our knowledge no studies on the effect of in vivo EP on immunogenicity against HIV1 elicited by DNA-VLP prime-boost immunizations have been reported. Therefore, in the present study we tested the effect of in vivo EP during DNA priming on immunogenicity in the heterologous DNA-VLP prime-boost immunization, in which HIV-1 VLP was produced by a stably transfected Drosophila S2 cell clone as we described before [40]. We primed mice twice with DNA plasmid encoding consensus B gp120 with or without in vivo EP and boosted them twice with HIV-1 VLP expressing the full length of consensus B HIV-1 gp160 plus c-di-GMP adjuvant along with mice injected with PBS control.

One interesting finding in this study is that in vivo EP during DNA priming not only significantly increases anti-HIV-1 gp120 total IgG responses, but also preferentially enhances anti-HIV-1 gp120 IgG2a, but not IgG1, responses (Fig. 3). IgG subclass switching is known to be strongly influenced by the prevailing cytokine environment and by the nature of the stimulating antigen [60-64]. For example, IL-4, a $\mathrm{T}_{\mathrm{H}} 2$ cytokine, preferentially induces switching to $\operatorname{IgG1}$ and $\operatorname{IgE}[60]$; whereas IFN- $\gamma$, a $\mathrm{T}_{\mathrm{H}} 1$ cytokine, preferentially induces switching to $\operatorname{IgG} 2 \mathrm{a}$, $2 \mathrm{~b}$ and 3 [64]. Here we showed in vivo EP during DNA priming also preferentially induces IgG2a switching. Indeed, we also found that DDVV + EP induces significantly higher percentages of HIV-1 envelope-specific IFN- $\gamma$-producing CD8 $\mathrm{T}$ cells compared to those induced by DDVV immunization (Fig. 7). Thus, tentatively in vivo EP during DNA priming may promote antigen processing and presentation, which results in more HIV-1 envelope-specific CD8 T cells to produce IFN- $\gamma$. The latter in turn induces IgG2a switching in HIV-1 envelope- 
314 specific B cells. Furthermore, among IgG subclasses, IgG2a and 2b are generally considered to

315 be the most potent for activating effector responses and dominate antiviral immunity [65, 66].

316 Indeed several recent studies on anti-HIV-1 or anti-influenza HA broadly neutralizing

317 human/mouse chimeric antibodies clearly demonstrated the requirement of interaction between

318 the IgG2a Fc region and the Fc $\gamma \mathrm{R}$ for protection against HIV-1 or influenza virus in vivo [67-69].

319 Moreover, in the follow-up immune correlation studies of RV144, human IgG1 (corresponding

320 to mouse IgG2a) and human IgG3 responses to V1/V2 loop of HIV-1 gp120 have been shown to

321 correlate with decreased HIV-1 transmission risk [70, 71]. Thus, the demonstration of in vivo EP

322 during DNA priming in heterologous DNA-VLP prime-boost preferentially increases anti-HIV-1

323 envelope-specific IgG2a responses could have an important implication in vaccine efficacy.

Another interesting finding in this study is that in vivo EP during DNA priming not only

325 significantly increases neutralization potency against autologous consensus B HIV-1 strain, but

326 also broadens neutralization breadth against heterologous and even heterosubtypic HIV-1 strains

327 including tier 2 strains, although the neutralization potency still needs to be improved (Fig. 5).

328 Passive infusion with broadly neutralizing monoclonal antibodies has demonstrated efficacy as

329 both preventive and therapeutic agents in humanized mouse and simian-human

330 immunodeficiency virus (SHIV) rhesus macaque models [72-81], more recently in chronic HIV-

3311 infected individuals [82]. It is conceivable that broadly neutralizing antibody responses, if they

332 are elicited by vaccinations, should play an important role in immune protection. Thus, the

333 demonstration in this study that in vivo EP during DNA priming significantly increases

334 neutralization potency and breadth of immune sera elicited by heterologous DNA-VLP

335 vaccination is very encouraging. However, due to limited amount of immune sera in mice in this

336 study we only tested neutralization activity of immune sera against six HIV-1 pseudotypes along 
337 with VSV-G control. Nevertheless, our results warrant more comprehensive testing of

338 neutralization potency and breadth of DDVV + EP sera in the future. Montefiori's group [83]

339 described a global panel of HIV-1 reference strains for standardized assessment of vaccine-

340 induced neutralizing antibodies. Therefore, it is better to test rabbit and monkey immune serum

341 samples against this global panel. Finally, by using competitive inhibition assay Zhang et al.

342 showed that neutralization activity against $\mathrm{BC}$ recombinants elicited by in vivo EP in the DNA-

343 protein prime-boost regimen is mediated by CD4BS antibodies [26]. Thus it is interesting to

344 determine what neutralization epitopes are recognized by DDVV + EP sera.

345 Still another finding in this study is that in vivo EP during DNA priming significantly 346 enhances HIV-1 envelope-specific CD8 T cells that secreted IFN- $\gamma$, IL-2 and/or TNF- $\alpha$ (Fig. 7).

347 It has been shown that immunization of rhesus macaques with live rhesus cytomegalovirus

348 vector encoding SIV gag, pol, rev, nef, tat and envelope provides a powerful stimulation of SIV349 specific CD8 T cells that control and eliminate virus in 50\% of animals $[5,6]$. Thus, although as 350 a delivery vehicle replication competent rhesus CMV vector can hardly be compared to in vivo 351 EP during DNA priming in this study, the demonstration that DDVV + EP immunization 352 significantly enhances HIV-1 envelope-specific CD8 T cells should still have important 353 implications in vaccine efficacy.

\section{Conclusion}

355 Taken together our results indicate that in vivo EP during DNA priming in DDVV 356 immunization preferentially increases $\mathrm{HIV}-1$ envelope-specific $\mathrm{T}_{\mathrm{H}} 1$ cytokine-mediated $\operatorname{IgG} 2 \mathrm{a}$ 357 responses and significantly enhances the potency and the breadth of neutralizing antibody 358 responses including tier 2 viruses as well as HIV-1 envelope-specific CD8 T cell responses. Thus, 
359 our results warrant further comprehensive studies on this heterologous DDVV + EP regimen in 360 large animals.

\section{$361 \quad$ Authors' contribution}

PZ (Paul Zhou), XH designed study. XH, QQZ, XXH performed experiments. YFS and LFY provided critical reagents. PZ (Paul Zhou), XH, PZ (Ping Zhu) analyzed data. PZ (Paul

364 Zhou) and $\mathrm{XH}$ wrote the manuscript with the help of all the authors. All authors read and 365 approved the final manuscript.

\section{Acknowledgements}

367 The authors wish to thank Dr. L. Naldini at the University Torino Medical School, Torino, 368 Italy for lentiviral transfer vector, Dr. B. H. Hahn at the University of Pennsylvania for DNA 369 plasmids encoding consensus B and C HIV-1 envelope protein, Dr. Linqi Zhang at the Tsinghua 370 University for DNA plasmid encoding CNE3. Cell line TZM.bl, pNL4-3.luc.R-E- transfer vector 371 and DNA plasmids encoding Q168, Yu2 and $\mathrm{HxBc} 2$ envelope proteins were obtained through 372 the AIDS Research and Reference Reagent Program, Division of the AIDS, National Institute of 373 Allergy and Infectious Diseases, National Institutes of Health, Germantown, MD. These reagents 374 were originally developed and contributed by Drs. J. Kappes, X. Wu, N. Landau, R. Risser, J. 375 Overbaugh and E. Freed.

\section{Funding}

377 This work was supported by research grants from: the Chinese National Science Foundation 378 (\#31170871 and \#81361120406) and National Science and Technology Major Project 379 (\#2012ZX10001-008 and \#2014ZX10001-001) to Paul Zhou, the Chinese National Science 
380 Foundation (\#31425007 and \#31230018) to Ping Zhu, and the National Laboratory of 381 Biomacromolecules (\#2016KF02) to Paul Zhou and Ping Zhu.

382

383

384

385

386

387

388

389 


\section{References}

391 [1] McElrath MJ, Haynes BF. Induction of immunity to human immunodeficiency virus type-1 by 392 vaccination. Immunity. 2010;33:542-54.

393 [2] Rerks-Ngarm S, Pitisuttithum P, Nitayaphan S, Kaewkungwal J, Chiu J, Paris R, et al. Vaccination with

[3] Haynes BF, Gilbert PB, McElrath MJ, Zolla-Pazner S, Tomaras GD, Alam SM, et al. Immune-Correlates Analysis of an HIV-1 Vaccine Efficacy Trial. N Engl J Med. 2012;366:1275-86.

[4] Gottardo R, Bailer RT, Korber BT, Gnanakaran S, Phillips J, Shen X, et al. Plasma IgG to linear epitopes in the V2 and V3 regions of HIV-1 gp120 correlate with a reduced risk of infection in the RV144 vaccine efficacy trial. PloS one. 2013;8:e75665.

[5] Hansen SG, Ford JC, Lewis MS, Ventura AB, Hughes CM, Coyne-Johnson L, et al. Profound early control of highly pathogenic SIV by an effector memory T-cell vaccine. Nature. 2011;473:523-7.

[6] Hansen SG, Piatak M, Jr., Ventura AB, Hughes CM, Gilbride RM, Ford JC, et al. Immune clearance of highly pathogenic SIV infection. Nature. 2013;502:100-4.

[7] Hansen SG, Sacha JB, Hughes CM, Ford JC, Burwitz BJ, Scholz I, et al. Cytomegalovirus vectors violate CD8+ T cell epitope recognition paradigms. Science. 2013;340:1237874.

[8] Barouch DH, Picker L. Novel vaccine vectors for HIV-1. Nature reviews Microbiology. 2014;12:76571.

[9] Excler JL, Robb ML, Kim JH. Prospects for a globally effective HIV-1 vaccine. Vaccine. 2015;33 Suppl 4:D4-12.

[10] Excler JL, Michael NL. Lessons from HIV-1 vaccine efficacy trials. Current opinion in HIV and AIDS. 2016;11:607-13.

[11] Widera G, Austin M, Rabussay D, Goldbeck C, Barnett SW, Chen M, et al. Increased DNA Vaccine Delivery and Immunogenicity by Electroporation In Vivo. The Journal of Immunology. 2000;164:4635-40. [12] Liu J, Kjeken R, Mathiesen I, Barouch DH. Recruitment of antigen-presenting cells to the site of inoculation and augmentation of human immunodeficiency virus type 1 DNA vaccine immunogenicity by in vivo electroporation. Journal of virology. 2008;82:5643-9.

[13] Otten G, Schaefer M, Doe B, Liu H, Srivastava I, zur Megede J, et al. Enhancement of DNA vaccine potency in rhesus macaques by electroporation. Vaccine. 2004;22:2489-93.

[14] Otten GR, Schaefer M, Doe B, Liu H, Megede JZ, Donnelly J, et al. Potent immunogenicity of an HIV1 gag-pol fusion DNA vaccine delivered by in vivo electroporation. Vaccine. 2006;24:4503-9.

[15] Luckay A, Sidhu MK, Kjeken R, Megati S, Chong SY, Roopchand V, et al. Effect of plasmid DNA vaccine design and in vivo electroporation on the resulting vaccine-specific immune responses in rhesus macaques. Journal of virology. 2007;81:5257-69.

[16] Kulkarni V, Jalah R, Ganneru B, Bergamaschi C, Alicea C, von Gegerfelt A, et al. Comparison of immune responses generated by optimized DNA vaccination against SIV antigens in mice and macaques. Vaccine. 2011;29:6742-54.

[17] Dolter KE, Evans CF, Ellefsen B, Song J, Boente-Carrera M, Vittorino R, et al. Immunogenicity, safety, biodistribution and persistence of ADVAX, a prophylactic DNA vaccine for HIV-1, delivered by in vivo electroporation. Vaccine. 2011;29:795-803.

[18] Simon AJ, Casimiro DR, Finnefrock AC, Davies ME, Tang A, Chen M, et al. Enhanced in vivo transgene expression and immunogenicity from plasmid vectors following electrostimulation in rodents and primates. Vaccine. 2008;26:5202-9.

[19] Yin J, Dai A, Lecureux J, Arango T, Kutzler MA, Yan J, et al. High antibody and cellular responses induced to HIV-1 clade C envelope following DNA vaccines delivered by electroporation. Vaccine. 2011;29:6763-70. 
[20] Cristillo AD, Galmin L, Restrepo S, Hudacik L, Suschak J, Lewis B, et al. HIV-1 Env vaccine comprised of electroporated DNA and protein co-administered with Talabostat. Biochemical and biophysical research communications. 2008;370:22-6.

[21] Hirao LA, Wu L, Khan AS, Hokey DA, Yan J, Dai A, et al. Combined effects of IL-12 and electroporation enhances the potency of DNA vaccination in macaques. Vaccine. 2008;26:3112-20. [22] Muthumani G, Laddy DJ, Sundaram SG, Fagone P, Shedlock DJ, Kannan S, et al. Co-immunization with an optimized plasmid-encoded immune stimulatory interleukin, high-mobility group box 1 protein, results in enhanced interferon-gamma secretion by antigen-specific CD8 T cells. Immunology. 2009;128:e612-20.

[23] Kraynyak KA, Kutzler MA, Cisper NJ, Khan AS, Draghia-Akli R, Sardesal NY, et al. Systemic immunization with CCL27/CTACK modulates immune responses at mucosal sites in mice and macaques. Vaccine. 2010;28:1942-51.

[24] Belisle SE, Yin J, Shedlock DJ, Dai A, Yan J, Hirao L, et al. Long-term programming of antigen-specific immunity from gene expression signatures in the PBMC of rhesus macaques immunized with an SIV DNA vaccine. PloS one. 2011;6:e19681.

[25] Muthumani K, Wise MC, Broderick KE, Hutnick N, Goodman J, Flingai S, et al. HIV-1 Env DNA Vaccine plus Protein Boost Delivered by EP Expands B- and T-Cell Responses and Neutralizing Phenotype In Vivo. PLoS One. 2013;8(12):e84234. .

[26] Zhang M, Zhang L, Zhang C, Hong K, Shao Y, Huang Z, et al. DNA prime-protein boost using subtype consensus Env was effective in eliciting neutralizing antibody responses against subtype BC HIV-1 viruses circulating in China. Human vaccines \& immunotherapeutics. 2012;8:1630-7.

[27] Law M, Cardoso RM, Wilson IA, Burton DR. Antigenic and immunogenic study of membraneproximal external region-grafted gp120 antigens by a DNA prime-protein boost immunization strategy. Journal of virology. 2007;81:4272-85.

[28] Cristillo AD, Weiss D, Hudacik L, Restrepo S, Galmin L, Suschak J, et al. Persistent antibody and T cell responses induced by HIV-1 DNA vaccine delivered by electroporation. Biochemical and biophysical research communications. 2008;366:29-35.

[29] Mann JF, McKay PF, Fiserova A, Klein K, Cope A, Rogers P, et al. Enhanced immunogenicity of an HIV-1 DNA vaccine delivered with electroporation via combined intramuscular and intradermal routes. Journal of virology. 2014;88:6959-69.

[30] Li J, Valentin A, Kulkarni V, Rosati M, Beach RK, Alicea C, et al. HIV/SIV DNA vaccine combined with protein in a co-immunization protocol elicits highest humoral responses to envelope in mice and macaques. Vaccine. 2013;31:3747-55.

[31] Winstone N, Wilson AJ, Morrow G, Boggiano C, Chiuchiolo MJ, Lopez M, et al. Enhanced control of pathogenic Simian immunodeficiency virus SIVmac239 replication in macaques immunized with an interleukin-12 plasmid and a DNA prime-viral vector boost vaccine regimen. Journal of virology. 2011;85:9578-87.

[32] Knudsen ML, Mbewe-Mvula A, Rosario M, Johansson DX, Kakoulidou M, Bridgeman A, et al. Superior induction of T cell responses to conserved HIV-1 regions by electroporated alphavirus replicon DNA compared to that with conventional plasmid DNA vaccine. Journal of virology. 2012;86:4082-90. [33] Rosario M, Borthwick N, Stewart-Jones GB, Mbewe-Mvula A, Bridgeman A, Colloca S, et al. Primeboost regimens with adjuvanted synthetic long peptides elicit $T$ cells and antibodies to conserved regions of HIV-1 in macaques. Aids. 2012;26:275-84.

[34] Hutnick NA, Myles DJ, Hirao L, Scott VL, Ferraro B, Khan AS, et al. An optimized SIV DNA vaccine can serve as a boost for $\mathrm{Ad} 5$ and provide partial protection from a high-dose SIVmac251 challenge. Vaccine. 2012;30:3202-8. 
[35] Hallengard D, Applequist SE, Nystrom S, Maltais AK, Marovich M, Moss B, et al. Immunization with multiple vaccine modalities induce strong HIV-specific cellular and humoral immune responses. Viral immunology. 2012;25:423-32.

[36] Vasan S, Hurley A, Schlesinger SJ, Hannaman D, Gardiner DF, Dugin DP, et al. In Vivo Electroporation Enhances the Immunogenicity of an HIV-1 DNA Vaccine Candidate in Healthy Volunteers. PLoS One. 2011;6:e19252.

[37] Mpendo J, Mutua G, Nyombayire J, Ingabire R, Nanvubya A, Anzala O, et al. A Phase I Double Blind, Placebo-Controlled, Randomized Study of the Safety and Immunogenicity of Electroporated HIV DNA with or without Interleukin 12 in Prime-Boost Combinations with an Ad35 HIV Vaccine in Healthy HIVSeronegative African Adults. PloS one. 2015;10:e0134287.

[38] Vasan S. Electroporation-mediated administration of candidate DNA vaccines against HIV-1. Methods in molecular biology. 2014;1121:291-307.

[39] Sardesai NY, Weiner DB. Electroporation delivery of DNA vaccines: prospects for success. Current opinion in immunology. 2011;23:421-9.

[40] Yang L, Song Y, Li X, Huang X, Liu J, Ding H, et al. HIV-1 virus-like particles produced by stably transfected Drosophila S2 cells: a desirable vaccine component. Journal of virology. 2012;86:7662-76. [41] Buonaguro L, Visciano ML, Tornesello ML, Tagliamonte M, Biryahwaho B, Buonaguro FM. Induction of systemic and mucosal cross-clade neutralizing antibodies in BALB/c mice immunized with human immunodeficiency virus type 1 clade $A$ virus-like particles administered by different routes of inoculation. Journal of virology. 2005;79:7059-67.

[42] Hammonds J, Chen X, Fouts T, DeVico A, Montefiori D, Spearman P. Induction of neutralizing antibodies against human immunodeficiency virus type 1 primary isolates by Gag-Env pseudovirion immunization. Journal of virology. 2005;79:14804-14.

[43] Hammonds J, Chen X, Zhang X, Lee F, Spearman P. Advances in methods for the production, purification, and characterization of HIV-1 Gag-Env pseudovirion vaccines. Vaccine. 2007;25:8036-48. [44] McBurney SP, Ross TM. Human immunodeficiency virus-like particles with consensus envelopes elicited broader cell-mediated peripheral and mucosal immune responses than polyvalent and monovalent Env vaccines. Vaccine. 2009;27:4337-49.

[45] Persson RH, Cao SX, Cates G, Yao FL, Klein MH, Rovinski B. Modifications of HIV-1 retrovirus-like particles to enhance safety and immunogenicity. Biologicals. 1998;26:255-65.

[46] Sakuragi S, Goto T, Sano K, Morikawa Y. HIV type 1 Gag virus-like particle budding from spheroplasts of Saccharomyces cerevisiae. Proceedings of the National Academy of Sciences of the United States of America. 2002;99:7956-61.

[47] Roldão A, Mellado MCM, Castilho LR, Carrondo MJT, Alves PM. Virus-like particles in vaccine development. Expert Review of Vaccines. 2010;9:1149-76.

[48] Wen M, Arora R, Wang H, Liu L, Kimata JT, Zhou P. GPI-anchored single chain Fv--an effective way to capture transiently-exposed neutralization epitopes on HIV-1 envelope spike. Retrovirology. 2010;7:79. [49] Derdeyn CA, Decker JM, Sfakianos JN, Wu X, O'Brien WA, Ratner L, et al. Sensitivity of human immunodeficiency virus type 1 to the fusion inhibitor T-20 is modulated by coreceptor specificity defined by the V3 loop of gp120. Journal of virology. 2000;74:8358-67.

[50] Platt EJ, Wehrly K, Kuhmann SE, Chesebro B, Kabat D. Effects of CCR5 and CD4 cell surface concentrations on infections by macrophagetropic isolates of human immunodeficiency virus type 1. Journal of virology. 1998;72:2855-64.

[51] Talsma SS, Babensee JE, Murthy N, Williams IR. Development and in vitro validation of a targeted delivery vehicle for DNA vaccines. Journal of controlled release : official journal of the Controlled Release Society. 2006;112:271-9. 
[52] Wang L, Hu H, Yang J, Wang F, Kaisermayer C, Zhou P. High yield of human monoclonal antibody produced by stably transfected Drosophila schneider 2 cells in perfusion culture using wave bioreactor. Molecular biotechnology. 2012;52:170-9. [53] Matz J, Kessler P, Bouchet J, Combes O, Ramos OH, Barin F, et al. Straightforward selection of broadly neutralizing single-domain antibodies targeting the conserved CD4 and coreceptor binding sites of HIV-1 gp120. Journal of virology. 2013;87:1137-49. [54] Chen W, Kuolee R, Yan H. The potential of 3',5'-cyclic diguanylic acid (c-di-GMP) as an effective vaccine adjuvant. Vaccine. 2010;28:3080-5.

[55] Zhao YG, Peng B, Deng H, Chen G, Yang F, Shao M, et al. Anti-HBV immune responses in rhesus macaques elicited by electroporation mediated DNA vaccination. Vaccine. 2006;24:897-903.

[56] Pang WK, Zhao Y, Peng J, Peng B, Xu Y. Therapeutic protein production in vivo after electroporationassisted intramuscular gene delivery. Conference proceedings: Annual International Conference of the IEEE Engineering in Medicine and Biology Society IEEE Engineering in Medicine and Biology Society Annual Conference. 2005;6:6229-32.

[57] Wu X, Kong XP. Antigenic landscape of the HIV-1 envelope and new immunological concepts defined by HIV-1 broadly neutralizing antibodies. Current opinion in immunology. 2016;42:56-64. [58] Mouquet H, Scharf L, Euler Z, Liu Y, Eden C, Scheid JF, et al. Complex-type N-glycan recognition by potent broadly neutralizing HIV antibodies. Proc Natl Acad Sci U S A. 2012;109:E3268-77.

[59] Moore PL, Gray ES, Wibmer CK, Bhiman JN, Nonyane M, Sheward DJ, et al. Evolution of an HIV glycan-dependent broadly neutralizing antibody epitope through immune escape. Nature medicine. 2012;18:1688-92.

[60] Finkelman FD, Holmes J, Katona IM, Urban JF Jr, Beckmann MP, Park LS, et al. Lymphokine control of in vivo immunoglobulin isotype selection. Annu Rev Immunol. 1990;8:303-33. [61] Stavnezer J. Regulation of antibody production and class switching by TGF-beta. The Journal of Immunology. 1995;155:1647-51.

[62] Snapper CM, Mond JJ. Towards a comprehensive view of immunoglobulin class switching. Immunology Today. 1993;14:15-7.

[63] Mosmann TR, Coffman RL. TH1 and TH2 cells: different patterns of lymphokine secretion lead to different functional properties. Annu Rev Immunol. 1989;7:145-73.

[64] Mond JVos Q LA, Snapper CM. T cell independent antigens. Curr Opin Immunol. Current opinion in immunology. 1995;7:349-54.

[65] Coutelier JP, van der Logt JT, Heessen FW, Warnier G, Van Snick J. IgG2a restriction of murine antibodier elcited by viral infections. J Exp Med. 1987;165:64-9.

[66] Markine-Goriaynoff D, Coutelier JP. Increased Efficacy of the Immunoglobulin G2a Subclass in Antibody-Mediated Protection against Lactate Dehydrogenase-Elevating Virus-Induced Polioencephalomyelitis Revealed with Switch Mutants. Journal of virology. 2002;76:432-5.

[67] DiLillo DJ, Tan GS, Palese P, Ravetch JV. Broadly neutralizing hemagglutinin stalk-specific antibodies require FcgammaR interactions for protection against influenza virus in vivo. Nature medicine. 2014;20:143-51.

[68] Bournazos S, Klein F, Pietzsch J, Seaman MS, Nussenzweig MC, Ravetch JV. Broadly neutralizing antiHIV-1 antibodies require Fc effector functions for in vivo activity. Cell. 2014;158:1243-53.

[69] DiLillo DJ, Palese P, Wilson PC, Ravetch JV. Broadly neutralizing anti-influenza antibodies require Fc receptor engagement for in vivo protection. The Journal of clinical investigation. 2016;126:605-10.

[70] Chung AW, Ghebremichael M, Robinson H, Brown E, Choi I, Lane S, et al. Polyfunctional Fc-effector profiles mediated by IgG subclass selection distinguish RV144 and VAX003 vaccines. Science

573 translational medicine. 2014;6:228ra38. 
[71] Yates NL, Liao HX, Fong Y, deCamp A, Vandergrift NA, Williams WT, et al. Vaccine-induced Env V1V2 IgG3 correlates with lower HIV-1 infection risk and declines soon after vaccination. Science translational medicine. 2014;6:228ra39.

[72] Shingai M, Nishimura Y, Klein F, Mouquet H, Donau OK, Plishka R, et al. Antibody-mediated immunotherapy of macaques chronically infected with SHIV suppresses viraemia. Nature. 2013;503:27780.

[73] Barouch DH, Whitney JB, Moldt B, Klein F, Oliveira TY, Liu J, et al. Therapeutic efficacy of potent neutralizing HIV-1-specific monoclonal antibodies in SHIV-infected rhesus monkeys. Nature. 2013;503:224-8.

[74] Klein F, Halper-Stromberg A, Horwitz JA, Gruell H, Scheid JF, Bournazos S, et al. HIV therapy by a combination of broadly neutralizing antibodies in humanized mice. Nature. 2012;492:118-22.

[75] Diskin R, Klein F, Horwitz JA, Halper-Stromberg A, Sather DN, Marcovecchio PM, et al. Restricting HIV-1 pathways for escape using rationally designed anti-HIV-1 antibodies. The Journal of experimental medicine. 2013;210:1235-49.

[76] Veselinovic M, Neff CP, Mulder LR, Akkina R. Topical gel formulation of broadly neutralizing antiHIV-1 monoclonal antibody VRCO1 confers protection against HIV-1 vaginal challenge in a humanized mouse model. Virology. 2012;432:505-10.

[77] Ko SY, Pegu A, Rudicell RS, Yang ZY, Joyce MG, Chen X, et al. Enhanced neonatal Fc receptor function improves protection against primate SHIV infection. Nature. 2014;514:642-5.

[78] Balazs AB, Ouyang Y, Hong CM, Chen J, Nguyen SM, Rao DS, et al. Vectored immunoprophylaxis protects humanized mice from mucosal HIV transmission. Nature medicine. 2014;20:296-300.

[79] Balazs AB, Chen J, Hong CM, Rao DS, Yang L, Baltimore D. Antibody-based protection against HIV infection by vectored immunoprophylaxis. Nature. 2012;481:81-4.

[80] Pegu A, Yang ZY, Boyington JC, Wu L, Ko SY, Schmidt SD, et al. Neutralizing antibodies to HIV-1 envelope protect more effectively in vivo than those to the CD4 receptorl. Sci Transl Med. 2014;6:243ra88. .

[81] Rudicell RS, Kwon YD, Ko S-Y, Pegu A, Louder MK, Georgiev IS, et al. Enhanced Potency of a Broadly Neutralizing HIV-1 Antibody In Vitro Improves Protection against Lentiviral Infection In Vivo. Journal of virology. 2014;88:12669-82.

[82] Lynch RM, Boritz E, Coates EE, DeZure A, Madden P, Costner P, et al. Virologic effects of broadly neutralizing antibody VRCO1 administration during chronic HIV-1 infection. Sci Transl Med. 2015;7:319ra206.

[83] deCamp A, Hraber P, Bailer RT, Seaman MS, Ochsenbauer C, Kappes J, et al. Global panel of HIV-1 Env reference strains for standardized assessments of vaccine-elicited neutralizing antibodies. Journal of virology. 2014;88:2489-507. 
617 Table.1 The list of a panel of 10 15-mer peptides used for intracellular cytokine staining ${ }^{\mathrm{a}}$ 618

619 13-27 $7^{\mathrm{b}}\left(8766^{\mathrm{c}}\right)$ : LWRWGTMLLGMLMIC 113-127 (8791): QSLKPCVKLTPLCVT

620 305-319 (8839): KSIHIGPGRAFYTTG 353-367 (8851): GNKTIVFNQSSGGDP

621 412-426 (8866): CRIKQIINMWQEVGK 459-473 (8878): TEIFRPGGGDMRDNW

622 491-505 (8886): APTKAKRRVVQREKR 659-673 (8928): KWASLWNWFDITNWL

623 775-789 (8975): IVELLGRRGWEVLKY 823-837 (8969): VIEVVQRACRAILHI

624

$625{ }^{a}$ The 15 mer peptides were derived from consensus B of HIV-1 envelope sequence

$626 \mathrm{~b}$ The positions of amino acid residues of peptides

$627{ }^{c}$ The NIH AIDS Research and Reference Reagent Program catalog numbers of each peptide in 628 parenthesis.

629

630

631

632

633

634

635

636 


\section{Figure Legends}

638 Fig. 1 Immunogen characterization. A. western blot analysis of consensus B gp120 in culture 639 supernatants. Env: supernatants from L929 cells transfected with DNA plasmid encoding consensus gp120 alone; Env + rev: supernatants from L929 cells transfected with DNA plasmids 641 encoding consensus B gp120 and rev. Anti-gp120 antibodies: VRC01 and 2G12; anti-beta-actin

642 antibody (Sigma). B. FACS analysis of cell surface expression of consensus B gp160 using a 643 panel of anti-gp120 monoclonal antibodies VRC01, JM4, 2G12, 10-1074 and PGT128 along 644 with anti-influenza HA control antibody 100F4.

645 Fig. 2 Schematic diagram of DDVV and DDVV + EP immunizations and sampling. PBS: PBS 646 control; i.m. intramuscularly; s.c. subcutaneously; EP: in vivo electroporation.

647 Fig. 3 ELISA-binding antibody responses elicited in mice. Anti-HIV-1 envelope gp120-specific 648 total $\mathrm{IgG}$ responses (A), IgG1 responses (B), and IgG2a responses (C). $\mathrm{EC}_{50}$ : reciprocal serum 649 dilutions that result in $50 \%$ of maximum binding.

650

Fig. 4 Correlative analysis of anti-HIV-1 envelope gp120 responses. Correlation between total 651 IgG and IgG2a responses in DDVV + EP immunization (A) or in DDVV immunization (B).

652 Fig. 5 Neutralizing antibody responses elicited with DDVV or DDVV + EP immunization. 653 Neutralization activity of immune serum samples at 1:50 dilution against six HIV-1 pseudotypes 654 (consensus B, HxBc2, Yu2, Q168, CNE3, consensus C) and VSV-G pseudotypes control. The 655 percent neutralization was calculated as follows: (the amount of relative luciferase activity [RLA] 656 in pseudotype alone - the amount of RLA in pseudotype plus immune serum sample) / the 657 amount of RLA in pseudotype alone. Statistical analysis was performed between the means \pm 658 the SEM of a given pseudotype. 
659 Fig. 6 Correlative analysis of neutralizing antibody responses. Correlations between autologous 660 strain and tier 2 strain Yu2 (A) or Q168 (B) in DDVV + EP immunization.

661 Fig. 7 Intracellular cytokine staining analysis of CD8 T cell responses against a panel of HIV-1 662 envelope peptides. A. Gating strategies of percentages of CD8 T cells that secreted IFN- $\gamma$, IL-2 663 and/or TNF- $\alpha$. B to D. The percentages of CD8 T cells that secreted IFN- $\gamma$, IL-2, TNF- $\alpha$. E to H. 664 The percentages of CD8 T cells that secreted both IFN- $\gamma$ and IL-2, IFN- $\gamma$ and TNF- $\alpha$, or IL-2 and 665 TNF- $\alpha$. 


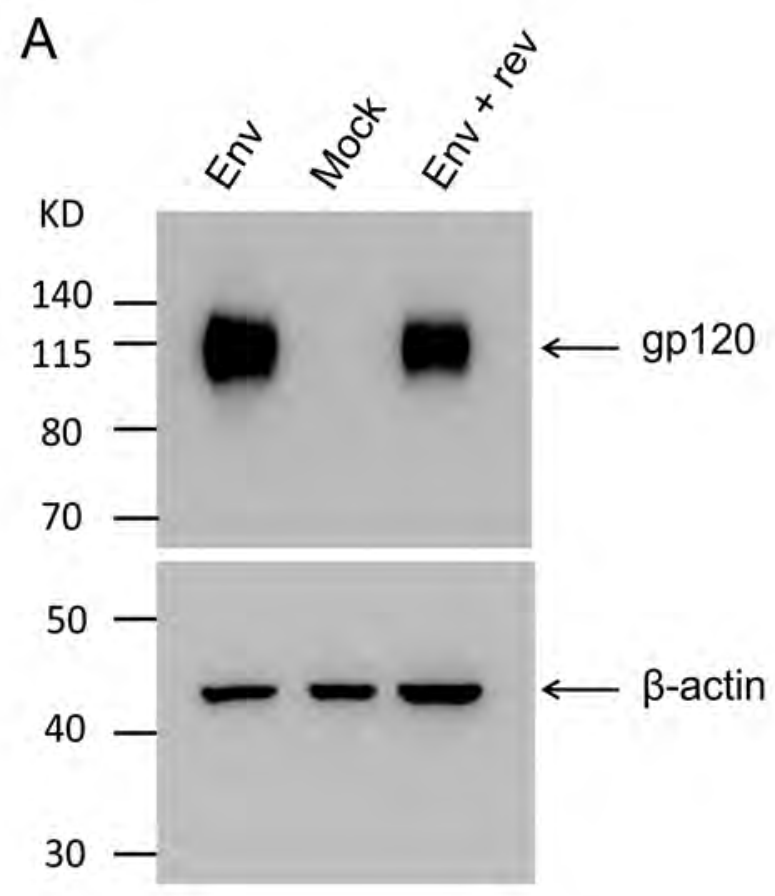

B

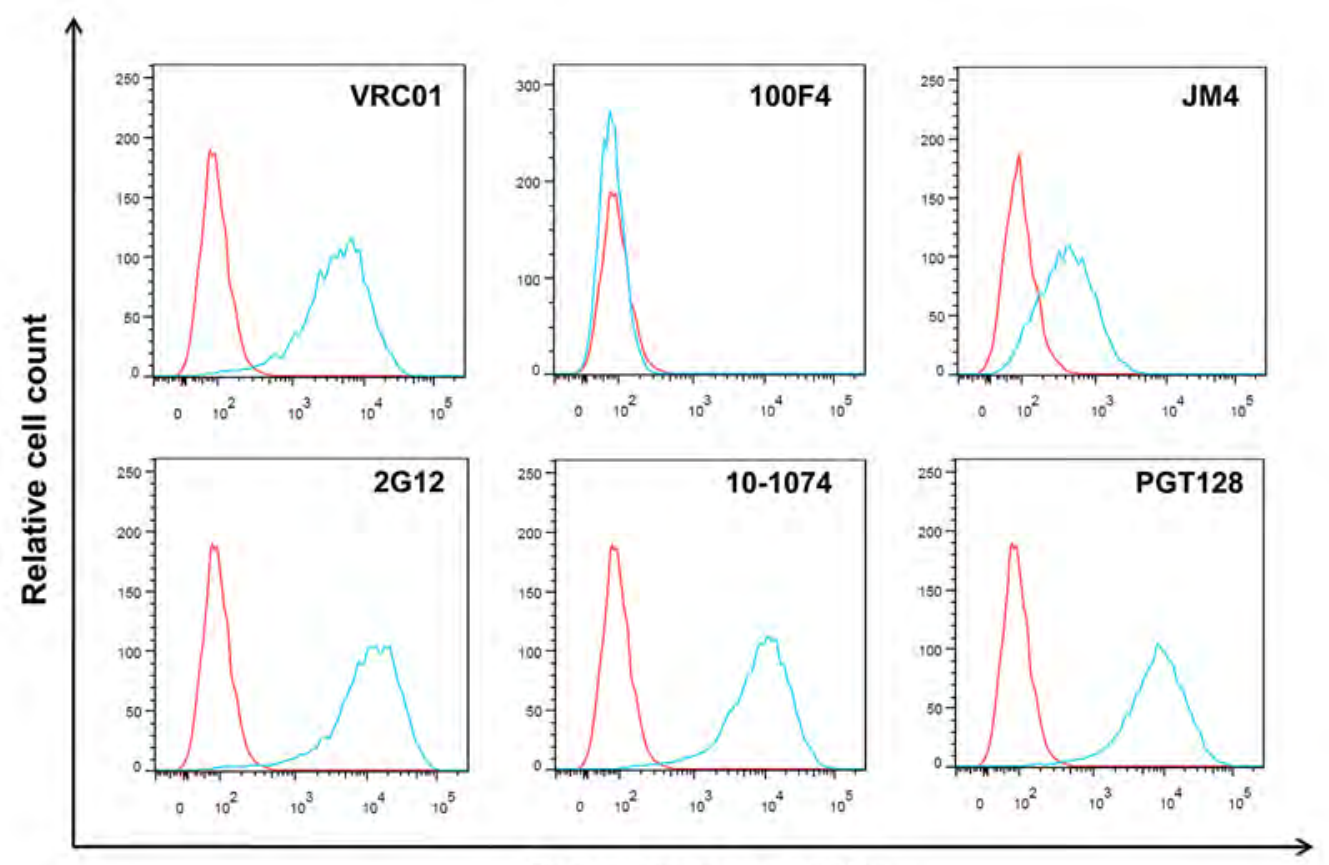

Fluorescence intensity 


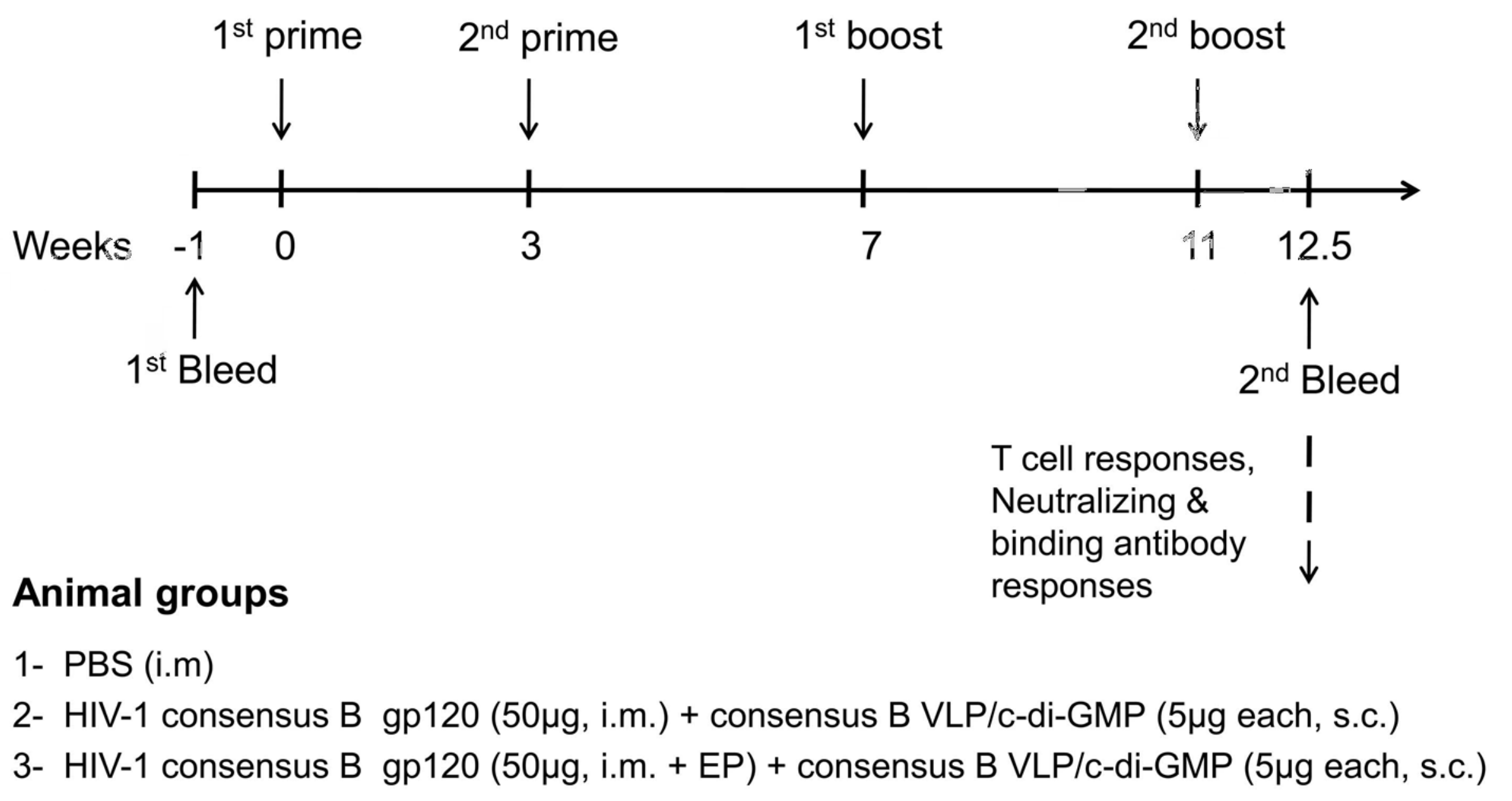



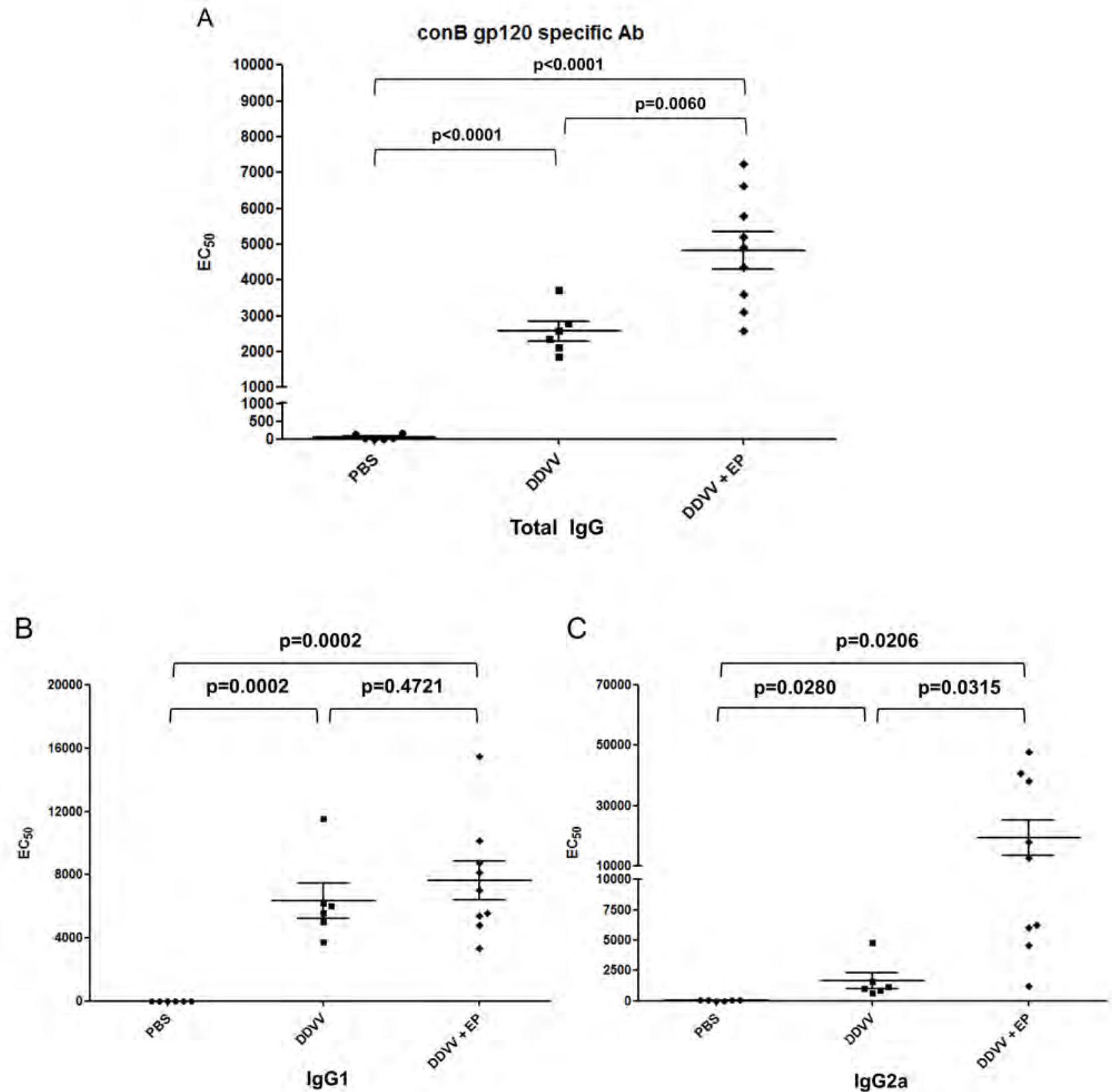

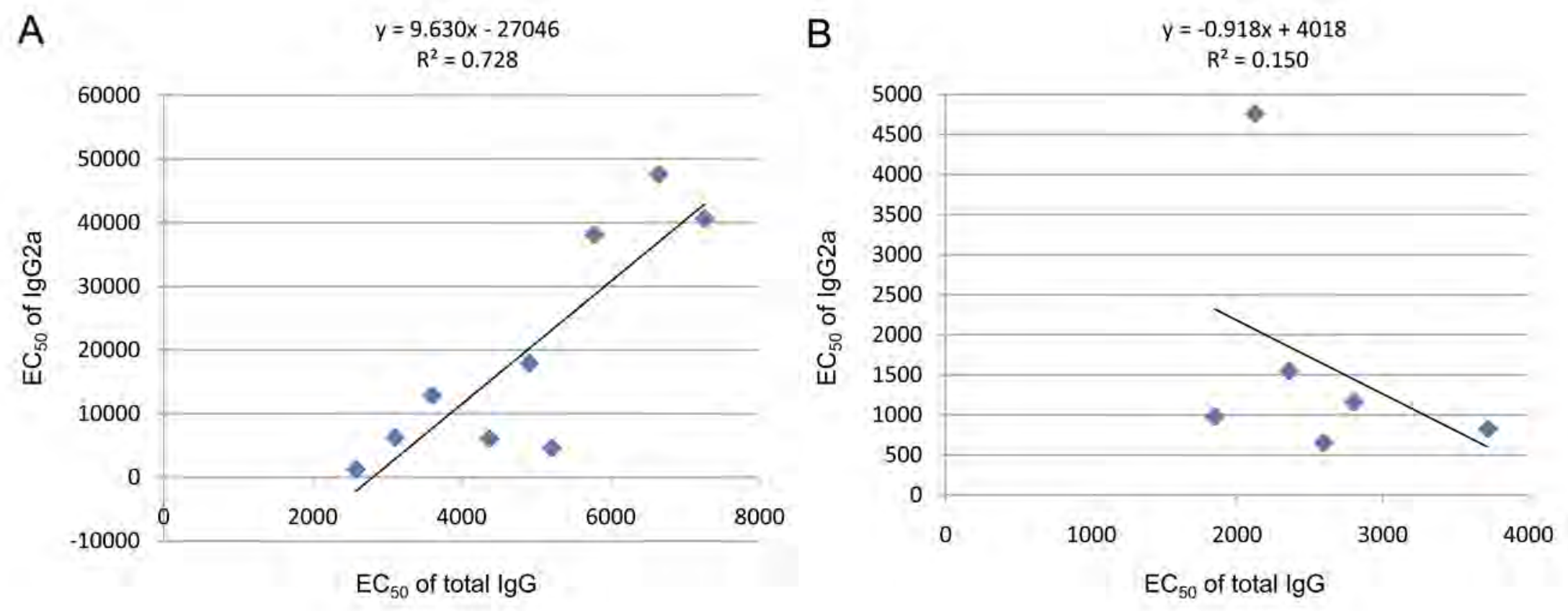

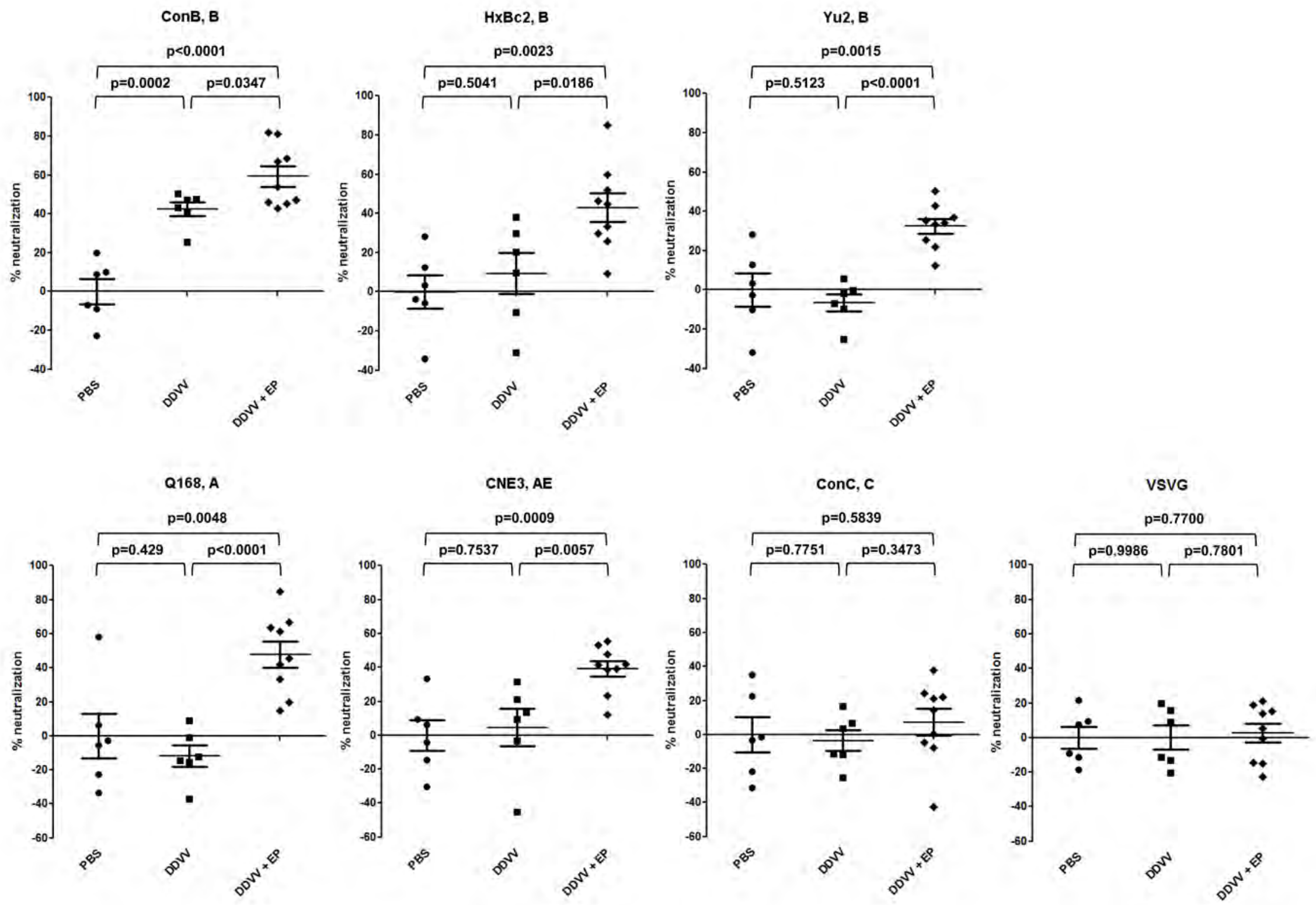

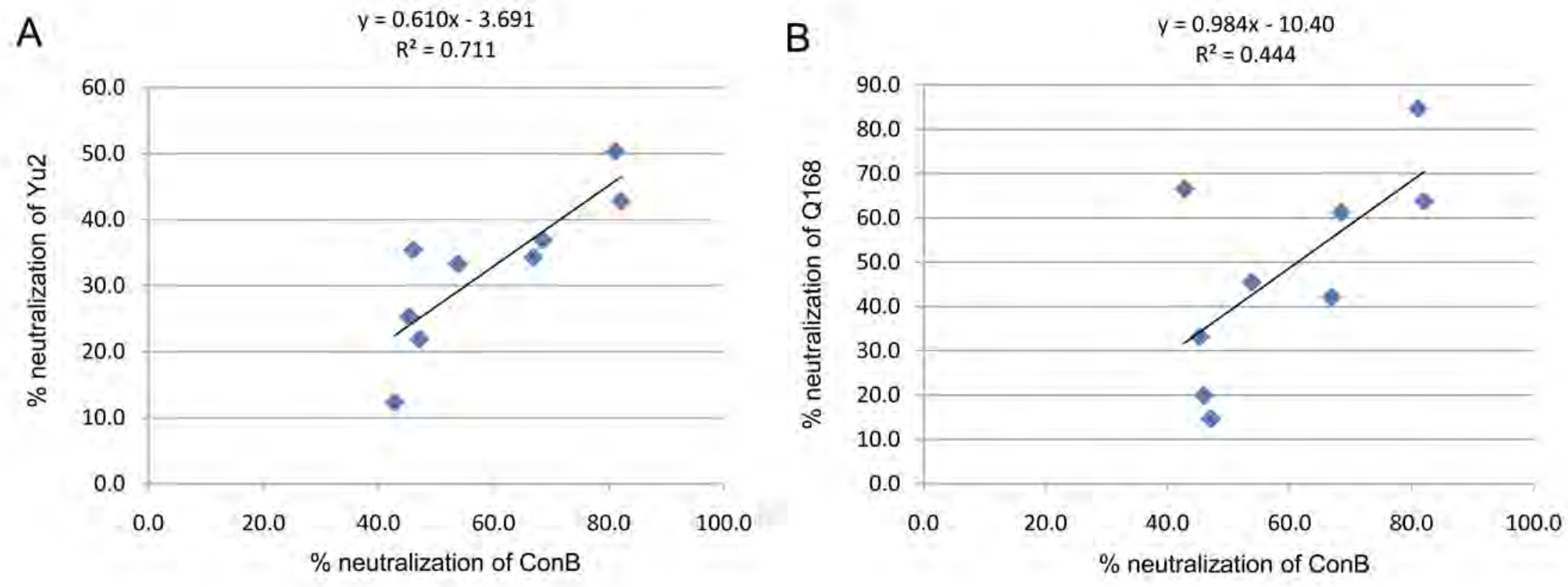

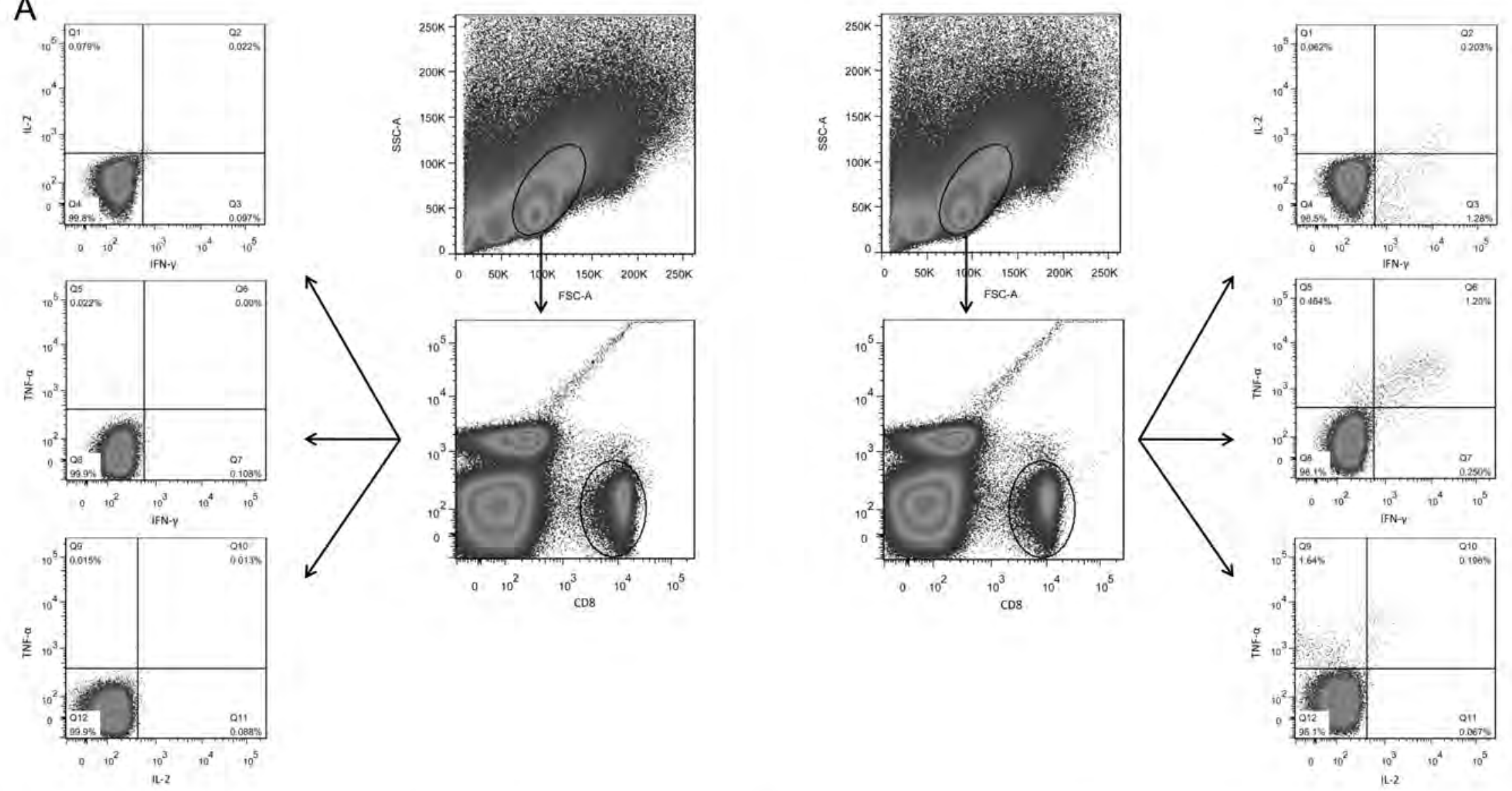

B
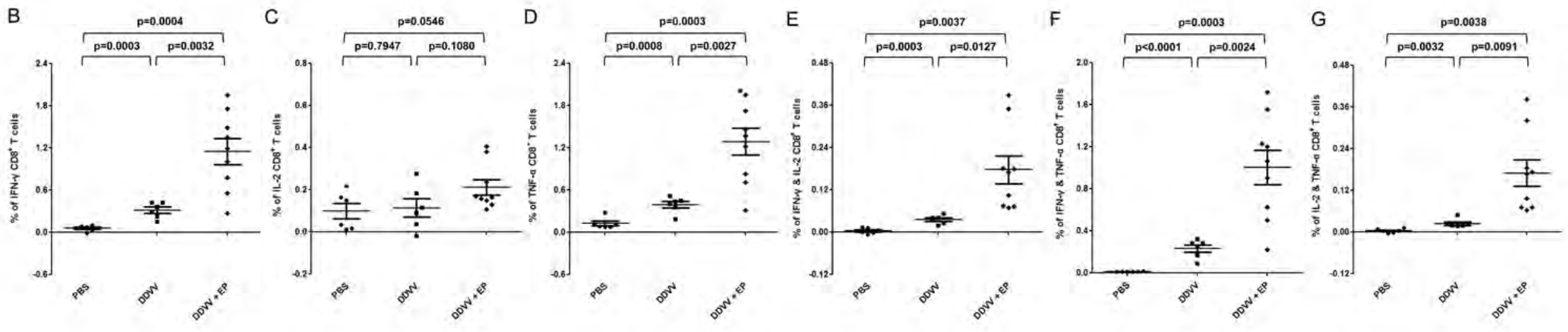